\title{
Optimization of process parameters using response surface methodology for the removal of phenol by emulsion liquid membrane
}

\author{
A. Balasubramanian, S. Venkatesan* \\ Anna University of Technology Tiruchirappalli, Department of Petrochemical Technology, Tiruchirappalli-620 024, Tamil Nadu, \\ India \\ "Corresponding author: e-mail: venkat.set@gmail.com
}

\begin{abstract}
Emulsion liquid membrane technique (ELM) was used for the extraction of phenol from synthetic and industrial effluents. In this study, the liquid membrane used for phenol removal was composed of kerosene as the solvent, Span- 80 as the surfactant and Sodium hydroxide as an internal reagent. Statistical experimental design was applied for the optimization of process parameters for the removal of phenol by ELM. The effects of process parameters namely, Surfactant concentration, membrane or organic to internal phase ratio $(\mathrm{M} / \mathrm{I})$ and emulsion to an external phase ratio $(\mathrm{E} / \mathrm{E})$ on the removal of phenol were optimized using a response surface method. The optimum conditions for the extraction of phenol using Response surface methodology were: surfactant concentration $-4.1802 \%$, M/I ratio: $0.9987(\mathrm{v} / \mathrm{v})$, and $\mathrm{E} / \mathrm{E}$ ratio: $0.4718(\mathrm{v} / \mathrm{v})$. Under the optimized condition the maximum phenol extraction was found to be $98.88 \%$ respectively.
\end{abstract}

Keywords: Emulsion Liquid membrane, Response Surface Methodology, Phenol, Surfactant.

\section{INTRODUCTION}

Phenol is a toxic substance and large amounts are presented in wastewaters which are generated from refineries, pharmaceutical and petrochemical operations and even in small quantities it is toxic to living organisms. The maximum phenol concentration for treated effluent is $1 \mathrm{ppm}^{1}$, while phenol concentration from the untreated industrial effluent can be in the range of $2.8-6900 \mathrm{ppm}$. Therefore, it is necessary to remove the phenol from industrial effluents before it is discharged into the water stream and a variety of treatment methods can be applied for phenol removal ${ }^{1-4}$. Popular among these are activated carbon adsorption, chemical oxidation, liquid membrane and biological treatment. Among the various wastewater treatment techniques, Liquid membrane (LM) separation provides a potentially powerful technique for effecting diverse separation operations. Compared to conventional processes, Emulsion liquid membrane (ELM) process has some attractive features, for example, simple operation, high efficiency, extraction and stripping in one stage, larger interfacial area, scope of continuous operation and a non-dependence on equilibrium consideration. $\mathrm{Li}$ was the first to introduce ELM with the purpose of increasing the interfacial area to shorten the diffusion path ${ }^{5-9}$.

In the application for wastewater treatment, ELM consists of water-oil-water system whereby the oil phase (membrane) acts as a selective barrier and encloses the aqueous stripping agent (internal phase). The emulsion will then disperse into the wastewater (external phase) for the extraction of the targeted solutes. Due to the concentration gradient between the two phases, the solutes transfer from the external phase into the membrane and are stripped down by the internal phase. The traditional optimization methods examine a single factor at a time while fixing all other variables at one level. Response surface methodology (RSM) being effective for responses that are influenced by many factors and their interactions ${ }^{\mathbf{1 0}}$. Analysis of variance (ANOVA) provides the statistical results and diagnostic checking tests, which enable researchers to evaluate the adequacy of the models ${ }^{11-13}$. Optimization of process parameters such as the concentration of the surfactant (SPAN 80), the ratio of Membrane phase to the internal phase in the membrane (M/I) and Emulsion to an external phase ratio $(\mathrm{E} / \mathrm{E})$ for the removal of phenol from synthetic solution using ELM were studied using Central composite design from a response surface method.

\section{MATERIALS AND METHODS}

\section{Experimental design}

Central composite design (CCD) was employed to determine the optimal conditions for the critical factors. The range and levels of experimental variables investigated in this study are presented in Table 1 . The actual values of independent variables $\left(X_{i}\right)$ were coded to xi according to equation (1) by assigning the lowest values listed in Table 1 as -1.68 and the highest values as +1.68 :

$x_{i}=\frac{X_{i}-\bar{x}_{i}}{\Delta x_{i}}, i=1,2,3 \ldots \ldots k$

Where $\mathrm{x}_{\mathrm{i}}$ is dimensionless value of independent variable, $X_{\mathrm{i}}$ represents the real value of the independent variable, $\bar{x}_{i}$ is the real values of the independent variable at the center point, and $\Delta \mathrm{x}_{\mathrm{i}}$ is the step change.

The CCD permits the response surface to be modeled by fitting a second-order polynomial with the number of experiments equal to $2 f+2^{f}+n$, where $f$ and $n$ are the number of factors and center runs, respectively $(f=3$, $n=6$ ). The repetition of central runs was carried out to

Table 1. Levels of different process variables in coded and un-coded form for the percentage removal of phenol

\begin{tabular}{|l|c|c|c|c|c|}
\hline \multirow{2}{*}{ Variables } & \multicolumn{5}{|c|}{ Ranges and Level } \\
\cline { 2 - 6 } & -1.68 & -1 & 0 & 1 & 1.68 \\
\hline $\begin{array}{l}\text { SPAN 80 (\%), } \\
\left(\mathrm{X}_{1}\right)\end{array}$ & 2 & 3 & 4 & 5 & 6 \\
\hline$(\mathrm{M} / \mathrm{I})(\mathrm{v} / \mathrm{v}),\left(\mathrm{X}_{2}\right)$ & 0.50 & 0.75 & 1.00 & 1.25 & 1.50 \\
\hline$(\mathrm{E} / \mathrm{E})(\mathrm{v} / \mathrm{v}),\left(\mathrm{X}_{3}\right)$ & 0.3 & 0.4 & 0.5 & 0.6 & 0.7 \\
\hline
\end{tabular}


provide information on the variation of the responses about the average, the residual variance, and eventually estimate the pure experimental uncertainty. A three factor-five coded level CCD, 20 runs shown in Table 1, was carried out to fit to the general model of equation (2) and to obtain economically optimum conditions for the removal efficiency.

$Y=\beta_{0}+\sum_{i=1}^{k} \beta_{i} X_{i}+\sum_{i=1}^{k} \beta_{i i} X_{i}^{2}+\sum_{i j=1(i \neq j)}^{k} \beta_{i j} X_{i} X_{j}$

Where $Y$ (the response or dependent variable) is the removal efficiency (\%), $\beta_{0}$ is the constant coefficient, $\beta_{\mathrm{i}}$ is the linear coefficient, $\beta_{\mathrm{ii}}$ is the coefficient of squared effect, $\beta_{\mathrm{ij}}$ is the coefficient of interaction effect, and $\mathrm{X}_{\mathrm{i}}$ and $X_{j}$ are the coded values of variables $i$ and $j$, respectively. The goodness-of-fit of the regression model and the significance of parameter estimates were determined through appropriate statistical methods. Optimization work on the experimental design, data analysis, response surfaces, and contour diagrams were performed by Design Expert 8.The statistical analysis of the results was carried out by ANOVA. It evaluates the model and its parameters, along with the determination of the individual and interactive influences of the factors on the phenol transfer from the bulk feed phase to the ELM phase by discovering the coefficients of the equation (2). The statistical significance was verified by the F-test in the program. The model terms were selected or rejected based on the probability value with $95 \%$ confidence level. Eventually, the response surface contour plots are generated in order to visualize the individual and the interactive effects of the independent variables.

\section{EXPERIMENTS}

$300 \mathrm{ppm}$ of Phenol solution and $0.75 \mathrm{M} \mathrm{NaOH}$ solution was prepared by dissolving them in distilled water. For ELM preparation, Span 80 was used as a surfactant due to the popularity as an emulsifier for liquid membrane. Kerosene was used as a diluent for the membrane. An emulsion of volume $12 \mathrm{~mL}$ was prepared by mixing the surfactant and diluent in a ratio of 4:96 together with $0.75 \mathrm{M} \mathrm{NaOH}$ solution as an internal stripping agent (internal phase) in a ratio of 1:1 by volume. The mixture of $\mathrm{W} / \mathrm{O}$ was then emulsified using a high speed homogenizer Ultra Turrax IKA-T25, operating at a rotational speed of $8000 \mathrm{rpm}$ for 6 min to obtain a milky white color liquid membrane. The parameters such as Surfactant concentration, $\mathrm{M} / \mathrm{I}$ ratio and $\mathrm{E} / \mathrm{E}$ ratio were varied to observe their effects on the percentage removal of phenol. Calibration curve for absorbance of phenol concentration was prepared to check the absorbance of phenol solution using different known concentration samples. The prepared emulsion and synthetic phenol solution (external phase)were taken in a beaker at 1:2 volume ratio and stirred by an IKA RW 20 overhead stirrer at the speed of $400 \mathrm{rpm}$ for $4 \mathrm{~min}$. A $4 \mathrm{~mL}$ of extracted phenol sample was taken and analyzed using UV-Vis Spectrophotometer Shimadzu-UV-2450 for phenol concentration. Detection of phenol observed at an absorbance value of $270 \mathrm{~nm}^{1}$. The concentration of phenol was estimated from the absorbance-phenol calibration curves. The response of the experiments measured in terms of percentage removal of phenol, which defined by equation (3).

Removal of Phenol $(\%)=\left[\frac{\left(c_{0}-c_{1}\right)}{c_{0}}\right] \times 100$

Where $c_{0}$ is the initial and $c_{1}$ is the final phenol concentration in the external phase.

\section{RESULTS AND DISCUSSION}

The process variable of ELM for the removal of phenol examined using RSM with CCD shown in Table 2. The experimental data were tested using statistical analysis, and a modified quadratic model proposed according to the results.

The regression model equation for the percentage of phenol removal was expressed as equation (4). Where $\mathrm{Y}$ is the permeation of phenol through ELM, $\mathrm{X}_{1}$ is the concentration of Span $80, X_{2}$ is $M / I$ and $X_{3}$ is $E / E$, the predicted removal plotted against the values, as illustrated in Fig.1. The value of regression coefficient $\left(\mathrm{R}^{2}=0.9793\right)$ is closer to one and indicates that the correlation is best suited in predicting the values for the removal system and the predicted values are found to be closer to the experimental results.

$Y=98.83+0.15 \times X_{1}+0.0084 \times X_{2}-0.27 \times X_{3}-0.19 \times X_{1} \times X_{2}+$

$0.022 \times X_{1} \times X_{3}-0.075 \times X_{2} \times X_{3}-0.42 X_{1}^{2}-0.23 X_{2}^{2}-0.47 X_{3}^{2}$

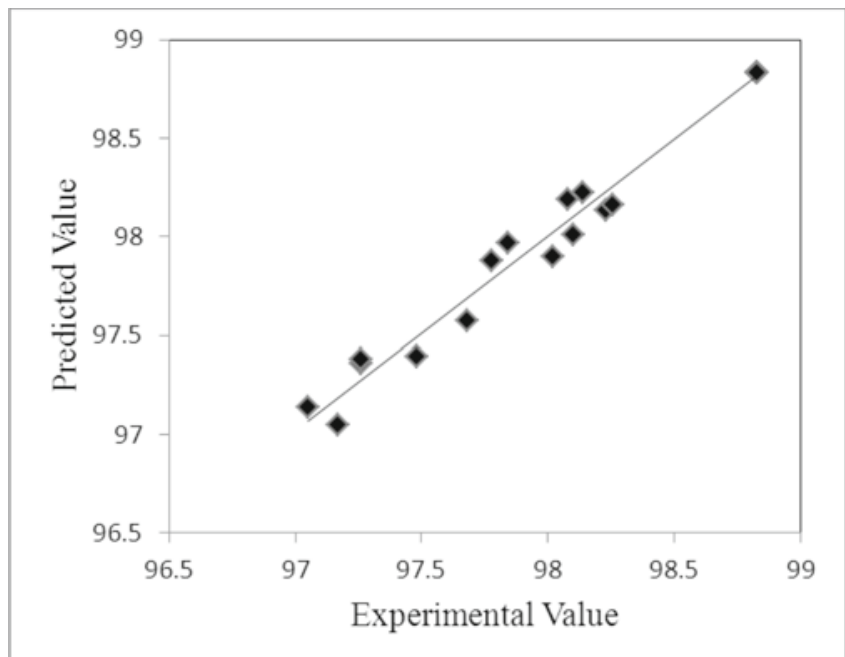

Figure 1. Predicted Versus Experimental values for percentage removal of phenol

ANOVA used to check the significance and fitness of the model. As shown in Table 1, the Model F-value of 52.47 implies the model is significant. There is only a $0.01 \%$ chance that a "Model F-Value" this large could occur due to noise. Values of "Prob > F" less than 0.0500 indicate the model terms are significant. In this case $\mathrm{X}_{1}, \mathrm{X}_{3}, \mathrm{X}_{1} \mathrm{X}_{2}, \mathrm{X}_{1}^{2}, \mathrm{X}_{2}^{2}$ and $\mathrm{X}_{3}^{2}$ are significant model terms. Values greater than 0.1000 indicate the model terms are not significant. The applied ANOVA for the removal of phenol provided in Table 3. The "Pred RSquared" of 0.8390 is in reasonable agreement with the "Adj R-Squared" of 0.9606. "Adeq Precision" measures the signal to noise ratio. A ratio of 20.381 indicates an adequate signal which is greater than 4 is desirable.

The plotted response surface curves were used to understand the interaction of the variables and to determine the optimum level of each variable for a maximum 
Table 2. CCD matrix along with experimental values of percentage removal of phenol

\begin{tabular}{|c|c|c|c|c|c|}
\hline \multirow{2}{*}{ Run } & \multirow{2}{*}{$\begin{array}{c}\text { Span } 80\left(X_{1}\right) \\
(\%)\end{array}$} & \multirow{2}{*}{$\begin{array}{c}\mathrm{M} / \mathrm{I}\left(\mathrm{X}_{2}\right) \\
(\mathrm{v} / \mathrm{v})\end{array}$} & \multirow{2}{*}{$\begin{array}{c}E / E\left(X_{3}\right) \\
(v / v)\end{array}$} & \multicolumn{2}{|c|}{ Phenol removal (\%) } \\
\hline & & & & Experimental & Predicted \\
\hline 1 & -1.00 & -1.00 & 1.00 & 97.05 & 97.14 \\
\hline 2 & 0.00 & 1.68 & 0.00 & 98.08 & 98.19 \\
\hline 3 & 1.00 & -1.00 & 1.00 & 97.78 & 97.88 \\
\hline 4 & -1.00 & 1.00 & -1.00 & 98.23 & 98.13 \\
\hline 5 & 0.00 & 0.00 & 0.00 & 98.83 & 98.83 \\
\hline 6 & -1.00 & -1.00 & -1.00 & 97.68 & 97.57 \\
\hline 7 & 1.00 & 1.00 & 1.00 & 97.26 & 97.36 \\
\hline 8 & 0.00 & 0.00 & 0.00 & 98.83 & 98.83 \\
\hline 9 & 0.00 & -1.68 & 0.00 & 98.26 & 98.16 \\
\hline 10 & 0.00 & 0.00 & 0.00 & 98.83 & 98.83 \\
\hline 11 & 1.68 & 0.00 & 0.00 & 98.02 & 97.90 \\
\hline 12 & 0.00 & 0.00 & -1.68 & 97.84 & 97.97 \\
\hline 13 & 1.00 & 1.00 & -1.00 & 98.10 & 98.01 \\
\hline 14 & 1.00 & -1.00 & -1.00 & 98.14 & 98.22 \\
\hline 15 & -1.00 & 1.00 & 1.00 & 97.48 & 97.39 \\
\hline 16 & 0.00 & 0.00 & 0.00 & 98.83 & 98.83 \\
\hline 17 & -1.68 & 0.00 & 0.00 & 97.26 & 97.36 \\
\hline 18 & 0.00 & 0.00 & 1.68 & 97.17 & 97.05 \\
\hline 19 & 0.00 & 0.00 & 0.00 & 98.83 & 98.83 \\
\hline 20 & 0.00 & 0.00 & 0.00 & 98.83 & 98.83 \\
\hline
\end{tabular}

Table 3. ANOVA for response surface quadratic model for percentage removal of phenol

\begin{tabular}{|c|c|c|c|c|c|c|}
\hline Source & $\begin{array}{l}\text { Sum of } \\
\text { Squares }\end{array}$ & $\begin{array}{l}\text { Degrees of } \\
\text { freedom }\end{array}$ & $\begin{array}{l}\text { Mean } \\
\text { Square }\end{array}$ & F Value & $\begin{array}{c}\text { p-value } \\
\text { Prob }>\text { F }\end{array}$ & Remarks \\
\hline Model & 7.18 & 9 & 0.8 & 52.47 & $<0.0001$ & Significant \\
\hline$X_{1}$ & 0.33 & 1 & 0.33 & 21.54 & 0.0009 & \\
\hline $\mathrm{X}_{2}$ & 0.00096 & 1 & 0.00096 & 0.063 & 0.8071 & \\
\hline$X_{3}$ & 1.01 & 1 & 1.01 & 66.17 & $<0.0001$ & \\
\hline$X_{1} X_{2}$ & 0.3 & 1 & 0.3 & 19.46 & 0.0013 & \\
\hline$X_{1} X_{3}$ & 0.00392 & 1 & 0.00392 & 0.26 & 0.6229 & \\
\hline$X_{2} X_{3}$ & 0.045 & 1 & 0.045 & 2.99 & 0.1146 & \\
\hline$X_{1}^{2}$ & 2.53 & 1 & 2.53 & 166.4 & $<0.0001$ & \\
\hline $\mathrm{X}_{2}^{2}$ & 0.77 & 1 & 0.77 & 50.86 & $<0.0001$ & \\
\hline $\mathrm{X}_{3}^{2}$ & 3.14 & 1 & 3.14 & 206.62 & $<0.0001$ & \\
\hline Residual & 0.15 & 10 & 0.015 & & & \\
\hline Lack of Fit & 0.15 & 5 & 0.03 & & & \\
\hline Pure Error & 0 & 5 & 0 & & & \\
\hline Cor Total & 7.33 & 19 & & & & \\
\hline
\end{tabular}

$\mathrm{SD}=0.12 ;$ mean $=98.07$; Coefficient of Variation $\%=0.13 ; \mathrm{R}$ Squared $=0.9793 ;$ Adjusted R Squared= 0.9606;

Predicted R Squared $=0.8390 ;$ Adequate Precision $=20.381$.

response. The circular nature of the contour signifies that the interactive effects between the variables are not significant and the optimum values of the test variables cannot be easily obtained. The response surface curves for the removal of phenol by ELM are shown in Figs. 2-4. Each 3D plot represents the number of combinations of the two-test variable. The maximum percentage removal of phenol is indicated by the surface confined in the smallest curve of the plot with the other variable maintained at zero levels. It is evident to the elliptical nature of the contours that the interaction between the individual variables is significant. The sequential quadratic programming in MATLAB 7 is used to solve the second-degree polynomial regression equations (4). The optimum values of test variables in coded units are $X_{1}=0.1801, X_{2}=-0.0110$ and $X_{3}=-0.2903$. They are converted into uncoded units for the actual values and the optimum values of the test variables were: $4.1802 \%$, M/I ratio: 0.9987(v/v), and E/E ratio: 0.4718(v/v). Under the optimal condition the maximum predicted efficiency was $98.88 \%$. 


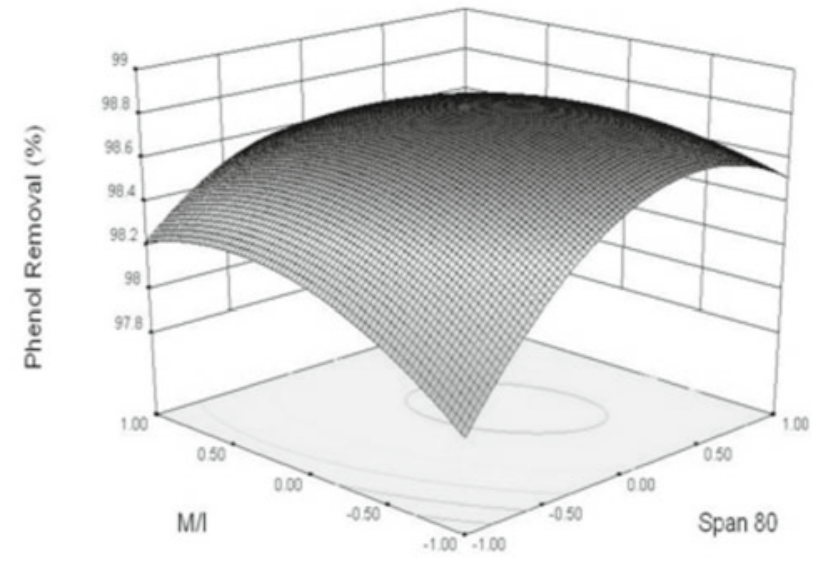

Figure 2. 3D surface plot of interaction between Span 80 and $\mathrm{M} / \mathrm{I}$ for percentage removal of phenol

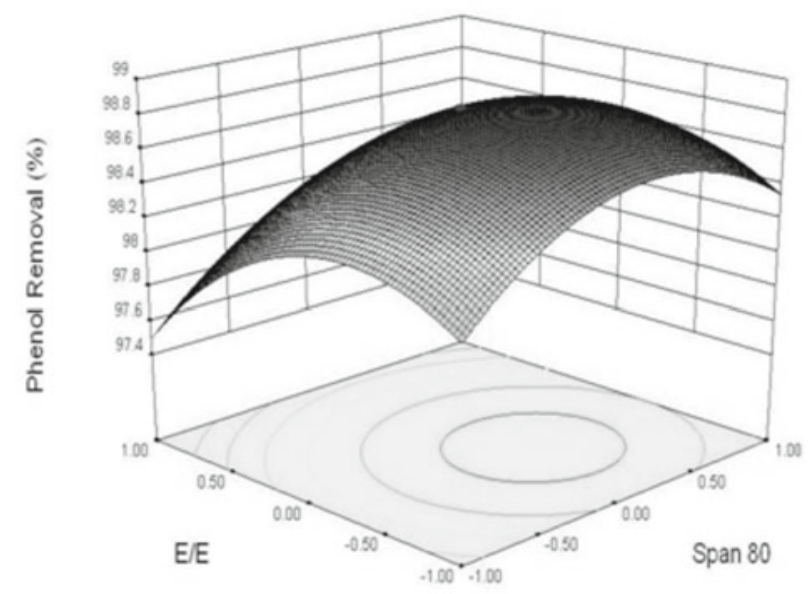

Figure 3. 3D surface plot of interaction between Span 80 and $\mathrm{E} / \mathrm{E}$ for percentage removal of phenol

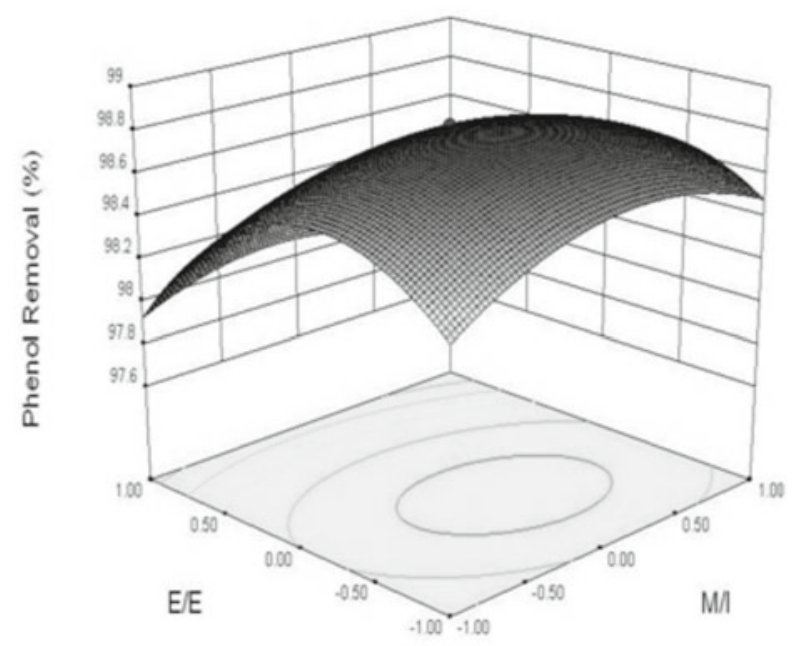

Figure 4. 3D Surface plot of interaction between $\mathrm{E} / \mathrm{E}$ and $\mathrm{M} / \mathrm{I}$ for percentage removal of phenol

\section{CONCLUSION}

ELM has been successfully applied to remove phenol from synthetic solution. Statistical design using response surface method could demonstrate the important influence of the three factors and an empirical relationship between the response and the variables was well achieved. The second order polynomial equation was adequate to predict the permeability as the response. ANOVA showed a high $R^{2}$ value of regression model equation $\left(R^{2}=0.9793\right)$ which ensures a sufficient adjustment of the model with the experimental data. Thus, the quadratic model equation could explain the performance of ELM for phenol permeation process with a high level of significance. The optimum conditions for the extraction of phenol using response surface methodology were: Surfactant concentration $4.1802 \%, \mathrm{M} / \mathrm{I}$ ratio: $0.9987(\mathrm{v} / \mathrm{v})$, and $\mathrm{E} / \mathrm{E}$ ratio: $0.4718(\mathrm{v} / \mathrm{v})$. At the optimized condition the maximum phenol extraction was found to be $98.88 \%$ respectively.

\section{ACKNOWLEDGEMENTS}

The authors wish to express their gratitude for the support extended by the Department of Science and Technology (DST) (Government of India), for financial support.

\section{LITERATURE CITED}

1. Ng, Y.S., Jayakumar, N.S. \& Hashim, M.A. (2010). Performance Evaluation of Organic Emulsion Liquid Membrane on Phenol Removal. J. Hazard. Mater. 184, 255-260. DOI:10.1016/j. jhazmat.2010.08.030.

2. Busca, G., Berardinelli, S., Resini, C. \& Arrighi, L. (2008). Technologies for the removal of phenol from fluid streams: a short review of recent developments. J. Hazard. Mater. 160, 265-288. DOI:10.1016/j.jhazmat.2008.03.045.

3. Teresa, A., Reis, M., Ondina de Freitas, M.F., Ismael, M.R.C. \& Carvalho, J.M.R. (2007). Recovery of phenol from aqueous solutions using liquid membranes with Cyanex 923. J. Membr. Sci. 305, 313-324. DOI:10.1016/j.memsci.2007.08.016.

4. Frankenfeld, J.W. \& Li, N.N. (1987). Handbook of Separation Process Technology. New York, NY: John Wiley \& Sons, Inc.

5. Urtiaga, A., Gutiérrez, R. \& Ortiz, I. (2009). Phenol recovery from phenolic resin manufacturing: Viability of the emulsion pertraction technology. Desalination. 245, 444-450. DOI: 10.1016/j.desal.2009.02.007.

6. Park, H.J. \& Chung, T.S. (2003). Removal of phenol from aqueous solution by liquid emulsion membrane. Korean $\mathrm{J}$. Chem. Eng. 20, 731-735. DOI: 10.1007/BF02706916.

7. Paulo Correia, F.M.M. \& Jorge de Carvalho, M.R. (2003). Recovery of phenol from phenolic Resin plant effluents by emulsion liquid membranes. J. Membr. Sci. 225, 41-49. DOI:10.1016/S0376-7388(03)00319-3.

8. Mortaheb, H.R., Amini, M.H., Sadeghian, F., Mokhtarani, B. \& Daneshyar, H. (2008). Study on a new surfactant for removal of phenol from wastewater by emulsion liquid membrane. J. Hazard. Mater. 160, 582-588. DOI:10.1016/j. jhazmat.2008.03.095.

9. Park, Y., Skelland, A.H.P., Forney, L.J. \& Kim, J.H., (2006). Removal of phenol and Substituted phenols by newly developed emulsion liquid membrane process. Water Res. 40, 1763-1772. DOI:10.1016/j.watres.2006.03.005.

10. Bezerra, M.A., Santelli, R.E., Oliveira, E.P., Villar, L.S. \& Escaleira, L.A. (2008). Response surface methodology (RSM) as a tool for optimization in analytical chemistry. Talanta. 76, 965-977. DOI:10.1016/j.talanta.2008.05.019.

11. Ghafari, S., Aziz, H.A., Isa, M.H. \& Zinatizadeh, A.A. (2009). Application of response surface methodology (RSM) to optimize coagulation-flocculation treatment of leachate using poly-aluminum chloride (PAC) and alum. J. Hazard. Mater. 163, 650-656. DOI:10.1016/j.jhazmat.2008.07.090.

12. Nosrati, S., Jayakumar, N.S. \& Hashim, M.A. (2011). Extraction performance of chromium (VI) with emulsion liquid membrane by Cyanex 923 as carrier using response surface Methodology. Desalination. 266, 286-290. DOI:10.1016/j.desal.2010.08.023.

13. Rajasimman, M. \& Karthic, P. (2010). Application of response surface methodology for the extraction of chromium (VI) by emulsion liquid membrane. J. Taiwan Inst. Chem. Engrs. 41, 105-110. DOI:10.1016/j.jtice.2009.04.010. 